\title{
Response to Crowley
}

Our article "Otitis media in laboratory rats" (Daniel, Means, Dressel, \& Loesche, 1973) was published as a precautionary note to researchers using rats for auditory research. In our article, postmortem middle-ear explorations revealed that the incidence of otitis media increased from approximately $18 \%$ to $50 \%$ when rats maintained under normal clean conditions (NIH, 1968) reached the age of 6 months. Based upon this observation and others reported in the same paper, we made the following recommedations for auditory researchers: (1) rats should be examined either by radiological methods (Grice et al, 1955) or by postmortem middle ear exploration, (2) younger rats should be used, (3) male rats should be used, and (4) brain surgery should be avoided when possible.

Further, we are not in disagreement with Crowley (1974) who pointed out that conditions of animal husbandry are related to the incidence of otitis media in rats. If "germ-free" or "barrier" facilities were available, their use would, in all probability, reduce or eliminate the incidence of otitis media in laboratory rats. While we find it hard to believe that using rubber gloves would reduce the incidence of otitis media, if the effectiveness of this precaution can be confirmed, we would add it to our list. However, our own data were not relevant to the importance of animal husbandry techniques, and thus we did not deal with the topic.
We would like to point out that Crowley's comments regarding ideal conditions for the maintenance of laboratory rats conflict with what are most likely representative laboratory conditions within specified acceptable standards (NIH, 1968). Whether present laboratory conditions for rats should be sterile rather than acceptably clean was not the purpose of our study; we merely reported the incidence of the disease in a normally clean laboratory. We still feel that investigators working on auditory problems with rats in laboratories that do not have facilities for "sterile" or "barrier" techniques would be well advised to follow our previously stated precautions.

Hal J. Daniel III

Larry Means

Patti Loesche

East Carolina University

\section{REFERENCES}

Crowley, D. E. Comment on otitis media in rats. Physiological Psychology, 1974, 2, 99-100.

Daniel, H. J., Means, L. W., Dressel, M. E., \& Loesche, P. J. Otitis media in laboratory rats. Physiological Psychology, 1973, 1, 7-8.

National Institute of Health. Guide for laboratory animal facilities and care. 3rd rev. ed., Publication No. 72-73. Public Health Service, No. 1024, Washington, D. C., 1968. 